\title{
A assertiva freudiana de que a psicanálise partilha uma Weltanschauung científica e a sustentação do desamparo como direção ética
}

Magali Milene Silva

\begin{abstract}
Resumo
Em 1932, Freud afirmou que a psicanálise partilha de uma Weltanschauung, de uma "visão de mundo" científica, apostando que a ciência sustentaria uma posição mais condizente com o desamparo que estrutura a condição humana. O presente artigo objetiva discutir a possibilidade de reconhecimento e sustentação do desamparo como direção ética proposta por Freud para o tratamento do sintoma neurótico e para a cultura, em contraponto ao modo "religioso" como a ciência é veiculada em nosso laço social atual.
\end{abstract}

\section{Palavras-chave:}

Weltanschauung; Psicanálise; Desamparo; Ética.

\section{The Freudian assertion that psychoanalysis shares a scientific Weltanschauung and the sustainment of helplessness as an ethical guidance}

\begin{abstract}
In 1932, Freud affirmed that psychoanalysis shares a Weltanschauung, a scientific "world view", wagering that science would sustain a more befitting position with the helplessness that structures human condition. The present article aims to discuss the possibility of the recognition and sustainment of helplessness as an ethical guidance proposed by Freud for the treatment of the neurotic symptom and for the culture, as opposed to the "religious" way science is conveyed in our current social bond.
\end{abstract}

Keywords:

Weltanschauung; Psychoanalysis; Helplessness; Ethics. 


\title{
La aseveración freudiana de que el psicoanálisis comparte una Weltanschauung científica y la sustentación del desamparo como una dirección ética
}

\begin{abstract}
Resumen
En 1932, Freud afirmó que el psicoanálisis comparte una Weltanschauung, una "visión de mundo" científica, apostando que la ciencia sostendría una posición más acorde con el desamparo que estructura a la condición humana. Este artículo tiene como objetivo la discusión de la posibilidad de reconocer y sostener el desamparo como dirección ética propuesta por Freud para el tratamiento del síntoma neurótico y para la cultura, en contraposición con el modo "religioso" en el que la ciencia es transmitida en nuestro lazo social actual.
\end{abstract}

\section{Palabras clave:}

Weltanschauung; Psicoanálisis; Desamparo; Ética.

\section{L'assertion freudienne de la psychanalyse en tant que partage d'une Weltanschauung scientifique et la proposition de la détresse en tant que direction éthique}

\begin{abstract}
Résumé
En 1932, Freud affirmait que la psychanalyse partageait une Weltanschauung, une «vision de monde » scientifique, en misant que la science soutiendrait une position plus appropriée par rapport à la détresse qui structure la condition humaine. Cet article a pour but de discuter la possibilité de reconnaître et de soutenir la détresse en tant que direction éthique proposée par Freud pour le traitement du symptôme névrotique et de la culture, par opposition à la manière " religieuse » dont la science est véhiculée dans notre lien social actuel.
\end{abstract}

\section{Mots-clés :}

Weltanschauung; Psychanalyse ; Détresse ; Ethique. 


\section{Introdução}

O objetivo deste artigo é discutir a proposição freudiana de que a psicanálise partilha a Weltanschauung científica. Para tanto, retomaremos a Conferência $\mathrm{XXXV}$, texto em que essa assertiva é apresentada, e a colocaremos em diálogo com outros textos de Freud, especialmente aqueles que discutem o tratamento analítico. Procuramos explorar a hipótese de que, na concepção freudiana, uma Weltanschauung científica implicaria uma posição de reconhecimento do desamparo e de trabalho com e a partir dele, e de que, nesse sentido, não sustentamos, em nossa época, que usa tanto o nome "ciência", uma posição verdadeiramente científica. É importante ressaltarmos que não se trata, nessa leitura, de uma discussão sobre a ciência e seus efeitos na cultura, mas sobre o que Freud nomeou Weltanschauung científica, ou seja, uma maneira de colocar-se diante do conhecimento, diante das respostas simbólicas, que visam a orientar a vida humana. Assim, o presente artigo sustenta que a Conferência XXXV pode ser lida como uma tentativa de situar a ética da psicanálise.

Freud proferiu em Viena, entre os anos 1915 e 1917, uma série de conferências que visavam a apresentar a técnica da psicanálise e sua teoria metapsicológica aos médicos. Em 1932, redigiu novas conferências, que, embora não tenham sido pronunciadas, marcaram o interesse em retomar lições introdutórias, levando em conta as modificações que a clínica impôs ao longo de sua obra e supondo uma transmissão oral ao fazer esse movimento. A Conferência XXXV, "A questão de uma Weltanschauung", última do ciclo proposto, aponta a preocupação freudiana em afirmar a vocação científica da psicanálise nesse que seria o legado para seus ouvintes imaginários. Que sentido podemos extrair dessa aproximação, tão cara a Freud, entre psicanálise e ciência para a consideração da ética da psicanálise?

\section{Uma resposta não totalizadora}

Freud começa a conferência reconhecendo a dificuldade de tradução do termo Weltanschauung, que, precariamente, poderíamos considerar como visão de mundo. Ele define que se trata de uma "construção intelectual que soluciona todos os problemas de nossa existência, uniformemente, com base em uma hipótese superior dominante, a qual, por conseguinte, não deixa nenhuma pergunta sem resposta e na qual tudo o que nos interessa encontra seu lugar fixo" (Freud, 1933 [1932]/1996g, p. 155). No entanto, no caso da ciência, a Weltanschauung seria um projeto permanentemente incompleto, uma aspiração ao futuro. É, assim, com uma aspiração científica, mesmo que ideal, que o criador da psicanálise propõe que o modo de tratar seu objeto de estudo é científico, embora possamos dizer que tanto o objeto quanto a metodologia de investigação que ele requer não são tradicionais na ciência. 
Ora, a psicanálise não pensa o mundo como a filosofia nem como a religião. Sua démarche é científica. E, fundamentalmente, não propõe uma aspiração totalizadora. De acordo com Mezan (2007), Freud aspira à consideração da psicanálise como uma ciência natural, o que Assoun (1996) chamou de concepção monista da ciência, pois, para Freud, existiria apenas uma ciência, uma Weltanschauung científica, cujo método é válido para toda ciência particular. Assim, é como um caso particular da visão de mundo científica que Freud nos apresenta a psicanálise. Como científica, ela estaria relacionada com constantes objeções e rejeições. Seu solo seria a pesquisa. Freud (1933 [1932]/1996g) defende que o progresso da ciência é lento, hesitante e laborioso, como o progresso de uma análise; posição que toma radicalmente ao longo de sua obra, com as constantes reformulações atribuídas por ele aos sempre renovados impasses trazidos pela clínica.

Situar a psicanálise como ciência natural é bastante interessante, pois desconsidera uma diferenciação de sua época entre ciências do espírito e ciências naturais. Mezan (2007) trabalha detidamente essa proposição. Conforme esse autor, as questões humanas eram discutidas na época de Freud pelas Geisteswissenschaften, ciências do espírito, em contraposição à Naturwissenschaften, ciência da natureza. Respectivamente, ciência que buscaria a compreensão (hermenêutica) de seu objeto e ciência que consideraria um objeto natural, com metodologia galileana e newtoniana. O método compreensivo requer a imersão do pesquisador no universo cultural do objeto de estudo, partilhando de sua rede de representações. Ao apostar nos modelos de uma ciência natural, de algum modo a singularidade do campo representativo impõe-se. Assim, é como pesquisador atento, mas externo, que Freud propõe-se uma escuta e uma direção para o tratamento.

A posição de Freud, ligada a certas concepções antropológicas de sua época, é a de que a Weltanschauung científica é superior, devendo as demais ser criticadas por ela e a ela conduzidas. Ele estabelece, desse modo, uma hierarquia entre animismo, religião e ciência, sendo essa última defendida claramente como mais elevada. No entanto, essa hierarquia deve ser relativizada quando Freud sustenta que todos os homens estão sujeitos a esses três modelos de visão de mundo, sendo a ciência a mais elevada não por ser mais completa, mas por ser a que melhor contempla a verdade do desamparo humano.

Essa é a hipótese com a qual gostaria de trabalhar neste texto. Sendo o desamparo a não orientação para a satisfação, o ponto de mal-estar que se situa como pedra angular para a consideração do inconsciente e do tratamento analítico, a Weltanschauung científica é a que apresenta a Freud uma posição mais afim ao trabalho por não partir de uma negação do desamparo, mas da marcha constante em contornos possíveis, embora parciais e provisórios. Ou seja, a Weltanschauung científica é considerada por Freud como concedendo um espaço para a verdade 
conflitiva em que os seres de cultura fundam-se; verdade que é fortemente velada no animismo e na religião. Dessa forma, dedica-se ao contraponto entre a visão religiosa e a científica:

Se quisermos dar uma noção da natureza grandiosa da religião, devemos ter em mente o que ela se propõe a fazer pelos seres humanos. Dá-lhes informações a respeito da origem e da existência do universo, assegura-lhes proteção e felicidade definitiva nos altos e baixos da vida e dirige seus pensamentos e ações mediante preceitos, os quais estabelecem toda a sua autoridade. Com isso ela preenche três funções. Com a primeira delas satisfaz a sede de conhecimento do homem; faz a mesma coisa que a ciência tenta fazer, com os seus próprios meios, e nesse ponto entra em choque com ela. É à segunda de sua função que a religião deve certamente a maior parte de sua influência. A ciência não pode competir com a religião quando esta acalma o medo que o homem sente em relação aos perigos e vicissitudes da vida, quando lhe garante um fim feliz e lhe oferece conforto na desventura. É verdade que a ciência nos pode ensinar como evitar determinados perigos e mostrar-nos existirem determinados sofrimentos que ela é capaz de combater com êxito; seria muito injusto negar que ela é um poderoso auxiliar do homem; há, contudo, muitas situações em que se vê obrigada a deixar o homem entregue ao sofrimento e apenas aconselhá-lo a resignar-se. Em sua terceira função, mediante a qual estabelece preceitos, proibições e restrições, a religião vai muito além da ciência. Isso porque a ciência contenta com investigar e estabelecer fatos, embora seja verdade que de suas aplicações se derivam normas e orientações quanto à conduta da vida. Em algumas circunstâncias, estas coincidem com aquelas que a religião oferece, mas, quando tal fato se verifica, os motivos de uma e de outra são diferentes (Freud, 1933 [1932]/1996g, p. 158)

Em “O futuro de uma ilusão” (1927/1996e), Freud articula a religião a uma promessa ilusória de amparo. Seria ilusão exatamente pela consideração psicanalítica do desamparo como estrutural, como a verdade negada do homem como ser de cultura, que é astutamente velada na religião. Conforme Freud articula, desde o "Projeto para uma psicologia científica" (1950 [1895]/1996h), o desamparo refere-se à impossibilidade de um bebê humano obter satisfação e mesmo sobreviver sem a mediação de outro, obrigando-o à função de comunicação. Ou seja, não sendo capaz de obter satisfação, é a outro que o bebê dirige-se em busca da satisfação; e, como esse outro está inserido na cultura, ela é mediada pelas representações que a satisfação virá apresentar-se para o bebê. Os homens, desamparados pelo fato da 
cultura, são obrigados a nela se alienaram, a ela se dirigirem para sobreviver, para obter satisfação, então perdida como plena, pois agora mediada. Ainda para Freud, não importa o quanto esse outro seja solícito ao bebê. Ele pode oferecer contornos, mas nunca uma solução definitiva ao desamparo. Posteriormente, em "O mal-estar na civilização” (1929-1930/1996f), Freud situa com mais clareza o desamparo como efeito do fato da cultura: como seres de cultura, não temos uma orientação natural para a satisfação. Esta deve ser construída mediada pelas representações. Um aparelho psíquico se constituiria como resposta, como defesa ao desamparo, que seria uma situação insuportável. Assim, o psíquico constitui-se em defesa a uma verdade insuportável da existência humana: o desamparo; isto é, o fato de que nenhuma resposta pode resolver definitivamente o problema da satisfação em que o humano funda-se. A religião, por sua vez, seria fortalecida por nosso desamparo, de que nos defendemos arduamente, e seria extremamente astuta, ao prometer o amparo para outra vida, outro plano ou outro momento da existência. Ao contrário, para Freud, a ciência enfrenta o desamparo do único modo que é possível aos seres de cultura: com alternativas parciais e provisórias.

\section{0 desamparo como direção ética}

Essas explanações freudianas nos apontam que uma visão de mundo religiosa pode estar presente fora de instituições claramente religiosas. Seria adequado afirmarmos que estariam presentes em toda promessa totalizadora de amparo, quer venham de igrejas, de seitas, de propostas políticas ou mesmo de consumo, como nos lembra Walter Benjamin (2013) no trabalho sobre o capitalismo como religião? O modo como a ciência é socialmente tomada atualmente não indicaria uma Weltanschauung religiosa, pois parece ser, aliada ao capitalismo, a promessa de explicação das origens e do futuro e a oferta de proteção e felicidade?

A formulação lacaniana do discurso universitário, apresentada em seu seminário "O avesso da psicanálise” (Lacan, 1969-1970/1992), é esclarecedora dessa articulação que opera em nosso laço social. Os discursos podem ser caracterizados como modo de manejo do ponto de impossível que nos atravessa como seres de linguagem, articulando posições para o sujeito em relação à mestria, ao saber e ao gozo (mais-de-gozar), produzindo laço. O discurso universitário produz um modo de articulação que não deixa lugar ao sujeito, ao imprimir a crença no saber com pretensões integrais. No discurso universitário, o saber é o agente, saber como aposta de que tudo é subsumido ao saber, que tudo pode ser enunciado sem enunciação. Saber genérico, sem sujeito que o enuncia, saber que tem horror à diferença, pois tudo pretende equivalente e contável. Assim, o saber dirige-se ao objeto na pretensão de integralizá-lo, de dizê-lo totalmente, tendo como efeito a produção do sujeito, efeito de mal-estar, que revela que a integralização do saber é uma impossibilidade de estrutura; sujeito como resto na produção incessan- 
te de saber. A verdade velada do discurso universitário é o significante mestre, o mandado simbólico que o significante mestre imprime ao círculo do discurso, convocando a saber sempre mais. Essa mestria, por não ser encarnada em um senhor específico (senão no mercado, na ciência etc.), é velada ao sujeito. $\mathrm{O}$ discurso universitário traz um mestre sutil e poderoso, imprimindo seu mandato, sem possibilitar ao sujeito situá-lo. Permite a veiculação de um saber diferente do saber mítico: o saber da ciência, que se constitui a partir da demissão da verdade da divisão do sujeito, a partir de um não querer saber da verdade como causa. $O$ saber engendrado pela ciência parte da equivalência entre os significantes - um significante só tem valor diferencial, permitindo operar com todos os objetos do mundo no mesmo plano (tal como o dinheiro no sistema capitalista). Nessa lógica, a verdade só interessa como formulação proposicional: falso, verdadeiro. A ciência introduz puras verdades numéricas, do que é contável, portanto equivalente.

$\mathrm{Na}$ articulação pelo discurso universitário, a ciência é tomada ao avesso do que Freud articula como Weltanschauung científica, pois é tomada como capaz de oferecer saber sem resto, fornecendo o semblante de sutura da divisão do sujeito, mesmo que incessantemente reconstruindo esse saber. Nesse sentido, poderíamos dizer, a partir do esquema trazido por Freud sobre as Weltanschauungen religiosa e científica, que se trata de um modo religioso de considerar a ciência. Assim, a astúcia do discurso universitário seria negar à ciência sua vocação verdadeiramente científica.

$\mathrm{O}$ afeto que mantém o sentimento religioso é vinculado por Freud ao totemismo, em que há aposta em um pai pleno, sem falta, que seria capaz de amparar; totemismo que é repetido na infância, no investimento na figura dos pais e para os quais retornamos quando não damos conta de atravessarmos o desamparo. Retomando o último item comentado sobre a religião, a orientação para o agir, Freud nos indica que ela também recorre à figura dos pais, que forneceriam a orientação para a satisfação. Assim, aquele que procura amparo na religião também se desincumbe de responsabilidade, pois a orientação moral vem do outro. Ao contrário, será que não poderíamos pensar que uma posição verdadeiramente responsável é aquela constituída em uma ética do desamparo? Ou seja, aquela que não fica à espera da proteção de um pai totêmico, que, como sabemos, protege e violenta?

Ao apresentar uma hierarquia entre as Weltanschauungen, Freud aponta que a ciência enfrenta o desamparo, ao passo que a religião lhe faz face com uma posição infantil de apelo a um pai todo poderoso, e o animismo, por meio da similitude da magia, opera no mundo guiado por seres míticos, em uma lógica semelhante. Como Freud havia articulado em "Totem e tabu” (1913/1996b), o animismo refere-se à crença na onipotência dos pensamentos, que não separa interno de externo; ou, traduzindo em outros termos freudianos, que trata a representação de palavra como representação de coisa. 
Diante do desamparo que se perpetua na vida adulta do homem civilizado, a religião ofereceria, segundo Freud, uma vantagem em relação ao animismo por localizar o mal, encarnando-o em imagens (demônios), ao que poderíamos acrescentar, usando um argumento de "O futuro de uma ilusão" (Freud, 1927/1996e), por adiar a promessa de amparo. A religião figuraria, nessa leitura, como uma resposta ao desamparo com fortes articulações simbólicas, baseada em nossas construções edípicas, em nossas fantasias de um amparo pleno.

Para Freud, animismo e religião estariam fadados ao fracasso, pois são tentativas de explicação da realidade que se baseiam em nossos desejos, em fantasias incondizentes com a realidade. Paradoxalmente, são respostas ao desamparo muito investidas de desejo, pois representam a promessa de amparo sem resto. Freud não usa esses termos no texto sobre a Weltanschauung, mas parece afirmar que a religião trabalha com o princípio do prazer, enquanto a ciência, com o princípio de realidade, pois seu critério de verdade é sua correspondência com o mundo externo. Talvez aqui possamos fazer uma inferência que falte ao texto, que é a consideração do além do princípio do prazer e da irredutibilidade do mal-estar, que marcaria exatamente a posição da psicanálise, pois, ao levar em conta a pulsão de morte na direção do tratamento, opera com algo que é deixado de fora do campo de consideração científica, conforme articula Lacan (1966/1998). Esse é um ponto interessante da argumentação freudiana, pois é em sua própria pena que, desde o texto sobre as afasias (Freud, 1891/2013), configura-se um núcleo irrepresentável para o aparelho de linguagem. Assim, se a ciência é definida por Freud como a busca de uma aproximação do real, uma correspondência sem resto entre as representações do conhecimento científico e o real, é apenas ideal, como é apontado por Freud desde o início do texto. Poderíamos dizer que a psicanálise partilharia de uma Weltanschauung científica, sendo ao mesmo tempo uma crítica de seus limites; isto é, a psicanálise constitui-se a partir do ponto em que a consideração de soluções totalizadoras é uma impossibilidade de estrutura.

Ao final da conferência com a qual estamos trabalhando, Freud dispõe-se a discutir outras Weltanschauungen, embora afirme não se sentir habilitado para tal análise. É bastante curioso que essa Weltanschauung seja nomeada por Freud (1933 [1932]/1996g, p. 171) anarquismo político, niilismo intelectual, para o qual a teoria da relatividade parece ter subido à cabeça:

Eles partem da ciência, é um fato, mas se empenham em forçá-la à anulação, ao suicídio; propõem-lhe a tarefa de ela própria abandonar o seu caminho, refundando, ela própria, as suas reivindicações. (...) segundo a teoria anarquista, a verdade não existe, não há conhecimento seguro do mundo externo. 
Freud, entretanto, insiste em sua aposta no conhecimento científico, mesmo fazendo a crítica de sua parcialidade. Vemos, desse modo, que ele faz uma crítica ao niilismo intelectual por sua posição de recusa ao trabalho constante convocado pelo desamparo e situa a psicanálise em um campo ético singular: reconhecendo o impossível do projeto humano e a precariedade das alternativas, mas, ainda assim, investindo na movimentação desejante nesse ponto, partilhada pela $\mathrm{Wel}$ tanschauung científica, pois apostaria na produção do conhecimento, mas a partir de sua consideração como parcial e provisório. Essa posição nos é apresentada com clareza em seu livro sobre o mal-estar: "O programa de tornar-se feliz que o princípio de prazer nos impõe não pode ser realizado; contudo não devemos - na verdade, não podemos - abandonar nossos esforços de aproximá-los da consecução, de uma maneira ou de outra" (Freud, 1929-1930/1996f, pp. 90-91).

Freud decide-se ainda, ao final da conferência, a criticar a visão de mundo marxista, que ele afirma dever ser levada mais a sério, e ressente de sua falta de informação:

A força do marxismo está, evidentemente, não em sua visão da história, ou nas profecias do futuro baseadas nela, mas sim na arguta indicação da influência decisiva que as circunstâncias econômicas dos homens têm sobre suas atitudes intelectuais, éticas e artísticas. Com isso foram descobertas numerosas correlações e implicações, que anteriormente haviam sido quase totalmente negligenciadas (Freud, 1933 [1932]/1996g, p. 173)

Mas Freud salienta que é preciso considerar também os aspectos afetivos aí envolvidos, tal como o que ele havia proposto na psicologia das massas. Ou seja, abre o caminho do que fariam os estudiosos da teoria crítica, pois Freud vai além e diz que, ao tornar-se uma visão de mundo totalizadora, o marxismo torna-se parecido ao status que está criticando; isto é, torna-se um sistema como a religião. "Embora o marxismo prático tenha varrido impiedosamente todos os sistemas idealísticos e ilusões, ele próprio desenvolveu ilusões que não são menos questionáveis e merecedoras de aprovação do que as anteriores" (Freud, 1933 [1932]/1996g, p. 175).

Ao nomear o sujeito com o qual a psicanálise opera de sujeito da ciência moderna, Lacan (1966/1998) atribui a emergência do sujeito ao ápice da exploração da dúvida que conduz Descartes à elaboração do cogito: "eu penso, eu sou”. Assim, o sujeito seria tributário de um momento de angústia, em que, na reflexão sobre o fundamento do saber, encontra-se a impossibilidade da certeza senão do próprio movimento. Ao sujeito do cogito, pontual e evanescente, só resta a certeza de que duvida. Dito de outro modo, o sujeito da consciência reflexiva confronta-se com o desamparo, tendo como efeito uma divisão, um corte, que instaura o sujeito do 
inconsciente. Como aponta Elia (2007), não é anódino que Lacan atribua o surgimento do sujeito a um momento de angústia. Talvez seja possível dizer que, ao articular o sujeito da psicanálise à ciência moderna, Lacan opera com a proposta freudiana de suportar uma Weltanschauung científica.

A atribuição de Lacan de que o sujeito da psicanálise é o sujeito da ciência situa a psicanálise como logicamente sincrônica à ciência moderna. A ciência moderna caracteriza-se, em especial, pela exigência de literalização a que a matematização procura atender. As notações matemáticas na ciência permitem operar com o real, não traduzi-lo em um saber sem resto. Assim, as mudanças de paradigma na ciência dizem respeito a comparar os efeitos operatórios do paradigma anterior e do novo, verificando o que cada um deixa de fora e que operações cada um permite verificar (Khun, 2009). Outra maneira de dizer que uma posição científica não é totalizadora. Mesmo que na proposta da ciência moderna todo objeto possa ser cientificamente abordado, atribuir o surgimento da ciência moderna ao cogito cartesiano é marcá-la com a consideração literal de que não se pode dizer tudo de nenhum objeto.

Fica, assim, o convite para sustentar uma posição ética que não queira recobrir totalmente o desamparo, eliminar o mal-estar, mas que não se recuse ao trabalho constante aí evocado: nem religião, nem niilismo. Será que poderíamos afirmar que Freud está propondo a sustentação (ou o atravessamento) do desamparo como uma ética?

\section{Trabalho e desamparo}

Freud nos falou do trabalho psíquico em algumas expressões presentes em suas obras, que gostaríamos de destacar: o trabalho do sonho (Freud, 1900/2015), o trabalho de elaboração (Freud, 1914/1996c) e também o trabalho da cultura (Freud, 1929-1930/1996f). O trabalho do sonho é o alicerce teórico sobre o qual Freud constrói suas elaborações sobre o funcionamento do inconsciente. Ele o institui como um trabalho de linguagem, que, por meio de condensações e deslocamentos, tece uma narrativa em que um desejo inconsciente expressa-se. Assim, um desejo inconsciente é trabalhado na elaboração de um sonho, como Freud deixa claro em uma nota acrescentada em 1925 ao livro sobre a intepretação dos sonhos, na qual esclarece que o inconsciente não é o conteúdo latente, mas o próprio trabalho de elaboração do sonho, a forma como o desejo inconsciente é moldado:

No fundo, o sonho não é outra coisa senão uma forma especial de nosso pensamento, possibilitada pelas condições do estado de sono. É o trabalho do sonho que produz essa forma, e só ele é o essencial do sonho, a explicação de sua singularidade. (Freud, 1900/2015, p. 533) 
Podemos dizer, dessa forma, que o inconsciente é um trabalho em torno do problema da satisfação, como nos é trazido pela noção de desamparo (Freud, 1950 [1895]/1996h). O desamparo marca um hiato entre a exigência de satisfação e a impossibilidade de alcançá-la como plena. Freud apresenta o desamparo como estrutural, não podendo ser ultrapassado, apenas singularmente contornado, camuflado. Podemos inferir, a partir dessas articulações freudianas, que a experiência de satisfação é acompanhada, no homem, de uma mediação, a linguagem, que vem por intermédio do outro humano de quem a criança depende. Como ele articula na monografia sobre as afasias (Freud, 1891/2013), um aparelho de linguagem que se constitui a partir de outro aparelho de linguagem. Freud trata, portanto, de um aparelho que se constitui em torno do problema da satisfação. Uma vez que o homem não é um animal natural orientado por instintos, precisa inventar modos de orientação para a satisfação. O problema é que essas formas serão sempre vividas como inventadas, inadequadas, deslocadas, estranhas, colocando um hiato estrutural entre a excitação e a satisfação. Diante dessa orientação que falta, algo é sentido como perdido, embora nunca tenha sido possuído, pois falta estruturalmente. Fundamento ausente que imprime ao trabalho psíquico constante.

A partir da escuta da histeria, Freud (1894/1996a) situa, de forma revolucionária, o sintoma como efeito de uma defesa contra uma incompatibilidade representativa quanto à impossibilidade de tudo ser representação. Conceitua o recalque como uma posição ética diante do desamparo, constituído a partir de uma defesa, que o nega. Assim, poderíamos situar o recalque primário. Resposta defensiva primeira, que nos constitui como atravessados pelo elemento cultural, quaisquer que sejam suas variações simbólicas. Todavia, essa defesa primária, que nos situa como castrados, sem orientação para satisfação, demanda constantemente trabalho em torno do que resta.

$\mathrm{Na}$ neurose, a resposta secundária do recalque fixaria um núcleo, que ordenaria o modo como o sujeito emerge, como uma repetição configura-se, condenando a um mesmo fracasso defensivo, ou seja, a um ponto de retorno do mal-estar. Ao refletir sobre o percurso de uma análise, Freud (1914/2017a) situa a repetição como a colocação em ato daquilo que o analisando não consegue trabalhar em palavras, propondo a análise como um trabalho de elaboração da repetição, atravessando-a e ultrapassando-a, "perlaboração". Parece indicar, aí, que a impossibilidade de a operação de defesa ser totalmente bem-sucedida condena a repetir, até que isso que insiste em repetir seja atravessado. Processo que, como Freud (1937/2017b) indicará posteriormente, não pode ser totalmente subsumido ao campo das representações, demandando uma construção, isto é, um reposicionamento diante do desamparo de que nos defendemos, que não seja apenas de negação, mas de trabalho com e a partir dele; ou seja, construção de um manejo singular, outro, da 
castração; além do sintoma. Assim, uma análise seria a possibilidade de retomar o desamparo e elaborar outro posicionamento ético diante da castração, que ainda seria uma defesa, mas que a leva em consideração; mudança no estatuto disso que o desamparo presentifica, de causa de angústia para causa de trabalho.

Mas, e o trabalho da cultura? Podemos dizer que a cultura, como mediação para a satisfação, configura o problema que a funda e a movimenta, sendo, constantemente, convocada a novas respostas, porém estas sempre insuficientes e provisórias. A condição do homem como ser de cultura demandaria constante trabalho de cada um e da cultura para a constituição de opções simbólicas de manejo do problema da satisfação. O trabalho da cultura tem, ao mesmo tempo, um aspecto coletivo e outro individual, derivando do fato de a constituição psíquica só se dar na relação com outros. O trabalho da cultura é solicitado pelo inacabamento inaugural do bebê humano (desamparo), que o constitui em sua dependência e relação; que o constitui atravessado pela linguagem. $O$ trabalho da cultura é o enlace entre a singularidade e a herança cultural, em que ambos se afetam - dependência constitutiva entre indivíduo e espécie (onto e filogenética). Enlace em que a história individual enoda-se de maneira única com a história comum, produzindo o campo da realidade psíquica. Essa relação não se faz, entretanto, sem um resto, um resto pulsional, que insiste para além da organização da realidade psíquica. Desse modo, o trabalho de cultura é permanentemente solicitado para dar conta desse resto, sem que, no entanto, seja possível eliminá-lo.

Freud (1929-1930/1996f, pp. 110-111) é claro ao expor que não se trata de um problema da civilização que precise ser aprimorado, mas de uma questão estrutural ao homem como civilizado, "de algo da natureza da própria função que nos nega satisfação completa e nos incita a outros caminhos", convocando ao trabalho da cultura.

\section{Algumas considerações sobre nossa época}

Parece que o modo como a ciência é discursivamente veiculada em nossa época aproxima-se muito mais do que Freud nomeou como uma Weltanschauung religiosa do que científica, uma vez que aparece como formulando postulados completos e estáveis no tempo. Um exemplo disso ocorre quando o argumento "é cientificamente comprovado" e é utilizado para encerrar uma discussão. Em uma Weltanschauung científica, ao contrário, essa afirmação seria um convite ao trabalho de debate.

Freud (1933 [1932]/1996g, pp. 176-177) finaliza a conferência que estamos considerando e sua série de conferências:

Senhoras e senhores: permitam-me que, para concluir, eu resuma o que tinha a dizer sobre a relação da psicanálise com a questão de uma Weltanschauung. A psicanálise não precisa de uma Weltanschauung; faz parte da ciência e pode 
aderir a uma Weltanschauung científica. Esta, porém, dificilmente merece um nome tão grandiloquente, pois não é capaz de abranger tudo, é muito incompleta e não pretende ser autossuficiente e construir sistemas.

Assim, uma Weltanschauung científica, se é que poderíamos chamar propriamente assim a visão de mundo decorrente da ciência, demanda trabalho constante. Não nos parece, entretanto, que a ciência seja tomada desse modo no laço social. Ao contrário, há certa forma de colocar a ciência, cada vez mais presente em nossa cultura, que se aproxima de uma Weltanschauung religiosa. Mostra disso está no modo como a mídia divulga pesquisas científicas, colocando o conhecimento produzido como total e inquestionável. Na verdade, talvez essa seja, inclusive, a forma como a ciência é considerada em nossa educação. Dito de outro modo, não parece que somos orientados por uma Weltanschauung científica como Freud a descreveu. Parece que não damos conta de atravessar o desamparo que nos marca, de "perlaborar" nossa falta constitutiva.

Podemos situar o modo como a ciência é veiculada no discurso universitário, em que o saber, na vertente da citação, ocupa o lugar de agente. Trata-se do saber como um mandato de ordem, saber que se pretende desencarnado de qualquer mestria, mas que acaba por subjugar o sujeito — por isso Lacan (1969-1970/1992) o chamou de mestre moderno. O saber imprime os objetos ao trabalho, é o próprio mais-de-gozar que é posto a trabalhar pelo saber - o saber universitário cria esse engodo de que são os objetos que trabalham e ditam seu ritmo, subordinando os sujeitos ao saber acéfalo e aos objetos. O sujeito é delegado ao lugar de produto. A verdade desse discurso é o significante mestre, verdade que estenografa a mestria que o universitário pretende disfarçar, mas que se exerce de maneira tirânica, subjugando o sujeito a efeito descartado da contabilidade das coisas. No entanto, o sujeito como produto marca a incompletude do discurso universitário, a impossibilidade do saber integral que esse discurso pretende. Porém, o funcionamento desse discurso é feito de tal modo que, tão logo o sujeito surja como produto de sua articulação, ele é reenviado ao circuito pelo significante mestre, mascarando a própria divisão do sujeito, que, no entanto, retorna na produção, lançando assim, o sujeito, em um incessante jogo com os objetos disponibilizados pelo mercado. Ou seja, segue buscando não saber do desamparo, apoiando-se em um saber que faz semblante de integral.

O discurso do analista, apresentado por Lacan (1969-1970/1992) como discurso que subverte o discurso do mestre, deve subverter também o discurso universitário, discurso do mestre moderno. No discurso do analista, é o objeto a que vem no lugar de agente, lugar ocupado pelo analista. Esse discurso toma como dominante aquilo que é rechaçado pelos demais discursos. O sujeito é convocado pelo discurso do analista a trabalhar a partir disso que o causa, a fim de evocar os 
significantes mestres que o assujeitam e questioná-los em sua mestria. Tem como efeito de verdade um saber singular - saber não todo, que comporta a enunciação. Ao tomar o objeto $a$ como agente, o discurso do analista convoca aquilo que emperra os discursos para a cena, convocando à movimentação discursiva, ao trabalho com e a partir do desamparo, ao invés de sua negação.

Gostaria de terminar com o convite freudiano de sustentar uma Weltanschauung científica. Assim, o diálogo entre psicanálise e ciência, mesmo que inerentemente atravessado por mal-estar, faz-se cada vez mais importante em nosso tempo, em que o modo como a ciência enreda-se nos jogos sociais de poder torna cada vez mais urgente que a psicanálise sustente sua posição de crítica às visões totalizadoras. Uma análise segue o caminho de desidealização de uma Weltanschauung. O trabalho de uma análise, nesse sentido, é uma crítica epistemológica, que conduz ao desvelamento e ao reposicionamento diante do desamparo. Aposta na possibilidade de outro modo de operar com o desamparo que não sua negação. Assim, uma análise conduz a uma Weltanschauung, que Freud chamou de científica, que não é a aposta de que a ciência é melhor, mas de que o melhor é uma aposta.

\section{Referências bibliográficas}

Assoun, P. L. (1996). Metapsicologia freudiana: uma introdução (D. D. Estrada, Trad.). Rio de Janeiro: Jorge Zahar.

Benjamin, W. (2013). O capitalismo como religião (R. R. Nélio Schneide, Trad.). São Paulo: Boitempo.

Elia, L. (2007). O conceito de sujeito (2a ed.). Rio de Janeiro: Jorge Zahar.

Freud, S. (1996a). As neuropsicoses de defesa. In S. Freud. Edição standard das obras completas de Sigmund Freud (Vol. 3) (J. Strachey, Trad.). Rio de Janeiro: Imago. (Trabalho original publicado em 1894)

Freud, S. (1996b). Totem e tabu. In S. Freud. Edição standard das obras completas de Sigmund Freud (Vol. 13) (J. Strachey, Trad.). Rio de Janeiro: Imago. (Trabalho original publicado em 1913)

Freud, S. (1996c). História do movimento psicanalítico: artigos sobre metapsicologia e outros trabalhos. In S. Freud. Edição standard das obras completas de Sigmund Freud (Vol. 14) (J. Strachey, Trad.). Rio de Janeiro: Imago. (Trabalho original publicado em 1914)

Freud, S. (1996d). Conferências introdutórias sobre psicanálise. In S. Freud. Edição standard das obras completas de Sigmund Freud (Vol. 15) (J. Strachey, Trad.). Rio de Janeiro: Imago. (Trabalho original publicado em 1915-1917)

Freud, S. (1996e). O futuro de uma ilusão. In S. Freud. Edição standard das obras completas de Sigmund Freud (Vol. 21) (J. Strachey, Trad.). Rio de Janeiro: Imago. (Trabalho original publicado em 1927) 
Freud, S. (1996f). O mal-estar na civilização. In S. Freud. Edição standard das obras completas de S. Freud (Vol. 21) (J. Strachey, Trad.). Rio de Janeiro. (Trabalho original publicado em 1929-1930)

Freud, S. (1996g). A questão de uma Weltanschauung. In S. Freud. Edição standard das obras completas de Sigmund Freud (Vol. 22) (J. Strachey, Trad.). Rio de Janeiro: Imago. (Trabalho original publicado em 1933 [1932])

Freud, S. (1996h). Projeto para uma psicologia científica. In S. Freud. Edição standard das obras completas de S. Freud (J. Strachey, Trad.). Rio de Janeiro: Imago. (Trabalho original publicado em 1950 [1895])

Freud, S. (2013). Sobre a concepção das afasias: um estudo crítico (E. D. Rossi, Trad.). Belo horizonte: Autêntica. (Trabalho original publicado em 1891)

Freud, S. (2015). A interpretação dos sonhos (Vol. 2) (R. Zwick, Trad.). Porto Alegre: L\&PM. (Trabalho original publicado em 1900)

Freud, S. (2017a). Recordar, repetir e perlaborar. In S. Freud. Fundamentos da clínica psicanalítica (C. Dornbusch, Trad.). Belo Horizonte: Autêntica. (Trabalho original publicado em 1914)

Freud, S. (2017b). Construções em análise. In S. Freud. Fundamentos da clínica psicanalítica (C. Dornbusch., Trad.). Belo Horizonte: Autêntica. (Trabalho original publicado em 1937)

Kuhn, T. S. (2009). A estrutura das revoluções científicas (B. V. Boeira \& N. Boeira, Trad.). São Paulo: Perspectiva. (Coleção Debates).

Lacan, J. (1992). O seminário, livro 17: o avesso da psicanálise. Rio de Janeiro: Jorge Zahar. (Trabalho original publicado em 1969-1970)

Lacan, J. (1998). A ciência e a verdade. In J. Lacan. Escritos (V. Ribeiro, Trad.). Rio de Janeiro: Jorge Zahar. (Trabalho original publicado em 1966)

Mezan, R. (2007). Que tipo de ciência é, afinal, a psicanálise?. Natureza Humana, 9(2), 319-359. Recuperado em 23 agosto, 2019, de http://pepsic.bvsalud.org/scielo.php?script=sci_arttext\&pid=S1517-24302007000200005\&lng=pt\&tlng=pt

Recebido: 27/09/2019

Aprovado: 26/02/2020 
